\title{
COMUNICACIÓN DEL GERENTE EN INSTITUCIONES EDUCATIVAS DE RIOHACHA EN LA GUAJIRA
}

Communication of the manager in educational institutions of Riohacha in Guajira

Marleivis Cujia**

\section{RESUMEN}

El presente artículo tuvo como propósito analizar la comunicación del gerente en instituciones educativas de Riohacha en La Guajira, Se apoyó en los postulados teóricos de Sueiro (2016), González (2015), Davis (2010), Méndez (2009), Gómez, Ruiz y Martí (2008), entre otros. El tipo de investigación fue descriptivo con un diseño no experimental transeccional, la muestra estuvo constituida por tres (3) directivos y 42 docentes que conforman tres instituciones educativas conformando un total de 45 personas. Se utilizó como técnica la encuesta, fundamentada en un instrumento tipo cuestionario dirigido a todos los docentes y directivos. Entre las conclusiones, se puede mencionar que los elementos de la comunicación son relevantes para que se dé el acto comunicativo en cualquier institución. Además, los gerentes educativos deben interactuar continuamente con los docentes para la planificación de tareas, por tal motivo, los mensajes deben ser claros y precisos, situación que no se presenta siempre en dichas instituciones.

Palabras clave: Comunicación, elementos, mensajes, barreras de la comunicación.

RECIBIDO: Octubre 2018 ACEPTADO: Noviembre 2018

\section{ABSTRACT}

The purpose of this article was to analyze the manager's communication in educational institutions of Riohacha in La Guajira. He relied on the theoretical postulates of Sueiro (2016), González (2015), Davis (2010), Méndez (2009), Gómez, Ruiz and Martí (2008), among others. The type of research was descriptive with a

\footnotetext{
${ }^{*}$ Psicorientadora en Institución Etnoeducativa y Docente Catedrática Universidad de la Guajira - Colombia. PsicólogaUniversidad Antonio Nariño-Colombia. Especialista en Pedagogía para el desarrollo del aprendizaje Autónomo. Magister en Gerencia Educativa. Actualmente desarrollando II semestre Doctorado. Colombia. Correo electrónico:
} marle_cuija@hotmail.com 
non-experimental transectional design, the sample consisted of three (3) managers and 42 teachers who make up three educational institutions forming a total of 45 people. The survey was used as a technique, based on a questionnaire-type instrument aimed at all teachers and managers. Among the conclusions, it can be mentioned that the elements of the communication are relevant for the communicative act to take place in any institution. In addition, educational managers must interact continuously with teachers to plan tasks, for this reason, the messages must be clear and precise, a situation that is not always presented in these institutions.

Keywords: Communication, elements, messages, communication barriers.

\section{Introducción}

En el mundo de hoy, existen cambios tanto políticos, económicos, culturales, medioambientales, sociales, entre otros, que plantean nuevos retos a las empresas a nivel mundial, donde la exigencia en el marco organizacional se hace visible porque deben fortalecer una comunicación efectiva, mediante un dialogo asertivo que permita llegar a la comprensión de los mensajes o informaciones dentro o fuera de la compañía. En este orden, la comunicación ejerce una influencia en el entorno empresarial, convirtiéndose en un componente esencial para el éxito gerencial.

Visto desde esta idea, en las organizaciones educativas debe existir una comunicación eficaz entre todo el personal, los cuales deben poseer destrezas comunicacionales para desempeñarse eficientemente dentro o fuera del entorno institucional, claro está, es relevante, que los trabajadores tengan la mejor disposición para cooperar, planificar planes y proyectos, elaborar estrategias corporativas, manteniendo un diálogo asertivo donde las ideas fluyan constantemente para unificar criterios que ayudarán a la toma de decisiones.

En este orden, Chiavenato (2010), refiere que la comunicación es el flujo de información entre dos o más personas y su comprensión. Desde este contexto, los individuos se comunican a través de ideas, hechos, pensamientos, valores y mensajes, además, en las organizaciones puede establecerse de manera formal o informal y esta puede verse afectada por muchas barreras que la debilitan, en algunos de los casos la interrumpen o dificultan. 


\section{Comunicación del gerente en instituciones educativas de Riohacha en la Guajira}

En criterio de Escudero (2012), actualmente, algunas instituciones educativas u otras compañías venezolanas buscan romper paradigmas y transformarse en organizaciones inteligentes donde la comunicación se convierta en una herramienta clave para las personas que la establecen mediante diálogos, de tal manera que puedan lograr el éxito, mejorando así, las diferencias de criterios entre los docentes, gerentes y empleados. Por tal razón, esta comunicación debe estar basada en el respeto, la responsabilidad y la cultura organizacional.

A su vez, actualmente existen instituciones educativas que presentan algunos problemas internos entre todo el personal que labora en ellas, lo cual ha ocasionado malos entendidos entre ellos, y en consecuencia generan un clima organizacional tenso, dificultando el desempeño. Esto se evidencia cuando se evalúan los equipos de trabajo conformados por los docentes para el desarrollo de planes estratégicos, quedando ideas inconclusas porque estas se interrumpen por barreras entre ellos.

De tal manera, se pueden observar en algunos de los casos una serie de causas como el inadecuado estilo de dirección que es indiferente a los problemas de comunicación entre la gerencia y los trabajadores, además, los conflictos que pudiesen existir en una institución educativa, inciden en la toma de decisiones de los equipos de trabajo impidiendo el logro de objetivos; porque la comunicación carece de un dialogo asertivo.

Aunado a la idea anterior, se podrían generar una serie de consecuencias que pudiesen afectar el proceso de comunicación de cualquier institución educativa, como es el uso inadecuado del canal de comunicación, la falta de unificación de criterios, falta de cooperación de los equipos de trabajo, los cuales impiden una retroalimentación adecuada entre las partes, influyendo además, en el desempeño laboral ocasionando baja productividad o calidad en los servicios prestados, dificultando la coordinación de las actividades.

Por otra parte, si esta situación sigue ocurriendo en las organizaciones y esta se vería afectada porque podría existir distorsión en los mensajes, razón por la cual, la falta de comprensión de las informaciones que pudiesen existir entre los gerentes o 


\section{Marleivis Cujia}

Telos Vol. 21, No. 1 (2019). 192-220

directivos y empleados o docentes, interrumpen la retroalimentación, es decir, la comunicación en las instituciones educativas oficiales de Riohacha en Colombia específicamente en la Institución Sagrada Familia, Institución el Carmelo, Institución Nuestra Señora de los Remedios, que están ubicadas en el mismo distrito, con calendario tipo A todas representadas por un solo rector y trabajan con el nivel de básica secundaria. De ser así, pueden verse afectadas las actividades en cuanto los procesos para el logro de objetivos, además, podrían mantenerse los malos entendidos, trayendo como consecuencia una imagen educativa negativa.

Considerando lo anterior, este artículo tiene como propósito analizar la comunicación del Gerente en Instituciones Educativas de Riohacha en La Guajira, abordando la comunicación del gerente en las organizaciones educativas, el proceso de esta, además, sus elementos como son emisor, receptor y mensaje, conjuntamente, con las barreras las cuales pueden ser: personales, físicas o semánticas que en algunos de los casos siempre están presente afectando el acto comunicativo, incluyendo la metodología, los resultados y las reflexiones finales, con sus respectivas referencias bibliográficas.

\section{Fundamentación Teórica}

\section{Comunicación del Gerente en las organizaciones educativas}

Se puede definir la comunicación como el proceso que se utiliza para transmitir una información, ideas o sentimientos. Todos nacen el instinto de comunicarse para obtener un objetivo, al pasar del tiempo se van adquiriendo símbolos e implementando métodos para lograr una comunicación eficiente que permita el trabajo de equipo Al respecto, Munch y García (2015) definen la comunicación como el proceso a través del cual se transmite y recibe información en un grupo social. Asimismo, Robbins (2009) señala que ningún grupo puede existir sin la comunicación: ésta es la transmisión de significados entre sus miembros. Sólo 
mediante la transmisión de significados de una persona a otra se puede compartir información e ideas.

Desde este punto de vista, los centros educativos, como instituciones sociales que forman a niños y jóvenes requieren gerentes que faciliten el proceso de transmitir información, de manera que faciliten y creen condiciones para el desempeño y evaluación de los docentes, quienes deben cumplir con las constantes exigencias de preparación de formación de las futuras generaciones. Al respecto, Calderón et al., (2015), señalan que la comunicación implica un proceso de transmisión y recepción de mensajes, cuyos contenidos inciden en la mayoría de los casos, en la toma de decisiones y motivaciones laborales, porque a través de ella se pueden en gran medida controlar los comportamientos organizacionales, orientados al logro de las metas y mantener el trabajo cooperativo.

Según el autor, la comunicación es considerada una red que genera entendimiento entre las personas, en busca de coordinar las actividades que le son propias. Para lograr que una comunicación tenga éxito, no sólo su significado debe ser transmitido, sino también alcanzar entendimiento entre las personas a quien va dirigida, la forma como llega a los receptores ha sido definida como dirección de la comunicación.

En este sentido, Davis y Newstrom (2003), señalan que la comunicación es transferencia de información y comprensión entre dos o más personas, considerándola como un puente entre los hombres que les permite compartir los sentimientos y conocimientos adquiridos, sentido útil a la gerencia. Por lo tanto, cuando se habla de comunicación, generalmente se entiende como el proceso en el cual un elemento dirige un mensaje hacia otro para recibir una respuesta o reacción esperada. Aunque realmente la comunicación es un factor determinante en las relaciones que se establecen entre los individuos y en interrelación con el medio en donde se desenvuelven en la generalidad de los casos, sobre todo en el ámbito educativo, la respuesta esperada es sumamente difícil de evaluar por las múltiples influencias que reciben los individuos. 


\section{Marleivis Cujia}

Telos Vol. 21, No. 1 (2019). 192-220

En este orden, la gerencia educativa es un proceso a través del cual se hacen posibles los objetivos preestablecidos por una organización escolar. Esta puede centrarse en la eficacia de las estrategias, en la comunicación y en la evaluación, como es el caso particular de esta investigación, donde la comunicación gerencial se analiza en atención a la gestión del director y a las necesidades de evaluación del docente. Esto le adhiere a la comunicación, una condición de mediador entre los dos procesos cuando se atienden de manera integral, propiciando una comunicación en red, que minimice las barreras que se pueden presentar como vía para responder a las necesidades del recurso humano y exigencias técnicas de la gerencia.

En este sentido, Méndez (2009), concibe la gerencia educativa como un proceso social, estructural, objetivo intencional y representa un factor integrador $\mathrm{y}$ multiplicador de los recursos humanos, materiales, presupuestarios, físicos, ambientales, con el fin de lograr la eficiencia de la organización, así como alcanzar la efectividad social. La definición del autor, plantea que el término gerencia no es exclusivo de las organizaciones con fines de lucro, de allí, que haya sido adoptado por otros tipos de organizaciones, como las educativas, manteniendo para su aplicación efectiva, los criterios de eficiencia, efectividad y particularmente de productividad y excelencia académica, apoyados en estrategias socializadoras.

En consecuencia, el director como gerente de las escuelas básicas secundaria debe propiciar las condiciones para que los docentes gestionen el tránsito de los alumnos por la escolaridad, bajo ciertas exigencias curriculares e instruccionales, que integre los objetivos de la educación básica secundaria. De allí, la necesidad de evaluar la función del docente en cuanto a los procesos que cumplen y la dirección que asume, con el fin de precisar las condiciones y controles técnicos docentes que aplican y sincronización del componente pedagógico.

Esto reivindica en su práctica la planificación, coordinación, ejecución y control, que procura la función del director en el nivel de educación básica secundaria. Es evidente, que la gerencia educativa al contrario de la académica se 
diferencia en su intención y contexto de ubicación donde subyace el logro de los objetivos, y en las mayores ganancias es de carácter social, pero siempre con la menor inversión posible y el logro de objetivos colectivos y administrativos.

Los planteamientos hechos, reflejan la existencia de diferentes tipos de intenciones educativas alguna de las cuales deben ser gerenciadas y otras administradas, esto en el sentido nato de las definiciones. En este sentido, un gerente, director o rector escolar es un sujeto con conceptos, principios y teorías que la han estudiado y explicado para hacer comprensible una acción.

Robbins (2009) conceptualiza la comunicación como la transferencia y comprensión de significado. De esta forma, se involucra al emisor como elemento transmisor del mensaje y el receptor como el elemento que comprende el mensaje. En ese contexto, la comunicación debe incluir tanto la transferencia como la comprensión del significado, es decir, por muy buena que sea una idea no servirá si no se transmite y es comprendida por las personas. La comunicación efectiva, existe cuando una idea o un pensamiento se transmiten, de tal forma que el cuadro mental del receptor sea exactamente el mismo que el emisor.

Por otro lado, Requeijo (2010) plantea que la comunicación es un instrumento eficaz para ejecutar lo planificado. En este orden, la comunicación del gerente educativo, es útil para fortalecer las relaciones humanas, es decir, los directores o rectores de las instituciones educativas deben desarrollar un adecuado sistema de comunicación que permita elevar el entendimiento entre el personal que labora en estas, en pro de buscar la unificación de criterios para la toma de decisiones.

De este modo, Chiavenato (2010) plantea la comunicación como la manera de relacionarse con otra persona a través de datos, ideas, pensamientos y valores. Esto une a las personas para compartir sentimientos y conocimientos. Es por ello que las instituciones educativas no pueden existir ni operar sin comunicación, puesto que ésta es la red que integra y coordina todas sus dependencias. Considerar el ambiente humano resulta entonces determinante en el proceso comunicacional, del mismo modo, conocer las ideas y formas de comportamiento de los individuos con las que 


\section{Marleivis Cujia}

Telos Vol. 21, No. 1 (2019). 192-220

se interactúa permite mayores niveles de comprensión de los mensajes facilitando el intercambio de información.

En función a lo expuesto, los gerentes educativos utilizan la comunicación para transmitir información, donde se destaque el mensaje suministrado, el recibido, cómo lo utilizan y qué significado posee. Por ello, se comparte el criterio de la comunicación como un proceso vital relacionado con cambios efectivos que optimicen el proceso educativo.

\section{Proceso de la Comunicación}

Para que la comunicación, según Robbins y Coulter (2007) tenga lugar, es necesario un propósito, expresado como un mensaje a transmitir. Este pasa a través de una fuente (emisor) y un receptor. El mensaje es codificado (convertido en una forma simbólica) y luego enviado mediante algún medio (canal) al receptor, quien traduce nuevamente (decodifica) el mensaje originado por la fuente. El resultado es una transferencia de significados de una persona a otra.

Al respecto, afirma Chiavenato (2010), por el hecho de que el comunicarse implica transacciones entre las personas requiere de al menos dos personas la que envía el mensaje y la que lo recibe, a tal efecto, para que se lleve a cabo una comunicación efectiva debe existir siempre los siguientes elementos: un emisor, un transmisor, un receptor y un procedimiento.

En este orden, se acota que la comunicación es aquel proceso donde interactúan los individuos para emitir y recibir informaciones, mediante un canal que puede ser natural y artificial, utilizando el mismo código para codificar y decodificar los mensajes y pueda existir la retroalimentación, todo esto puede ocurrir en cualquier contexto tanto educativo como empresarial.

\section{Elementos del Proceso de Comunicación}


Como elementos de la comunicación se entiende al conjunto de factores que intervienen en el proceso comunicacional, permitiendo que se generen ideas que forman parte de la esencia de la misma (Requeijo 2010). A tal efecto, para que se realice el acto comunicativo se necesitan una serie de elementos relevantes, los cuales interactúan en diversos contextos, tratando de intercambiar mensajes que puedan ser codificados y decodificados al mismo tiempo. Cuando se trata de comunicar algo, se emite un contenido a una persona o a un público, utilizando para ello explicaciones, prácticas, debates, mediante la utilización de un mismo signo para comprenderse.

Por su parte, Verdever, Sellnow y Verdever (2016), afirma que en toda acción comunicativa intervienen una serie de elementos como el emisor, receptor, mensaje y contexto, encontrándose presente los dos primeros para entablar conversaciones de diversas índoles, reclamos, informaciones, estados anímicos, entre otros. De esto, se deduce que toda comunicación es vista como una herramienta que utilizan los seres humanos para que el emisor y receptor la interpreten, reproduzcan, mantengan y transformen el significado de las cosas.

Esto se lleva a cabo dentro de alguna cultura humana, convirtiendo el proceso comunicacional en la esencia de toda organización. La misma requiere de respuestas que demuestren interés, comprensión y preocupación de los actores que establecen los mensajes que quieren comunicar. Igualmente, para Bateman y Snell (2009), en todo proceso comunicacional, intervienen una serie de elementos que participan en la transmisión de significados de una persona a otra. Estos significados se llaman mensajes. Por tanto, los mismos dependen de las actitudes, las destrezas, el conocimiento del transmisor o emisor y el sistema sociocultural.

En el mismo orden de ideas, el autor Chiavenato (2010), afirma que los elementos participantes en la comunicación deben tener un grado de compromiso, autoestima alta, seguridad para que la participación en la organización sea más efectiva; y por ende los individuos deben colaborar en las actividades que se realicen dentro del contexto educativo para lograr el éxito empresarial. 
En tal sentido, todos los elementos nombrados con anterioridad, son relevantes para que se establezca una comunicación, ya sea a nivel personal, académico o institucional. Para que la misma sea posible, necesita que el emisor receptor - mensaje y medio, interactúen adecuadamente y puedan conducir ideas, informes, sentimientos que afecten a los individuos o a los grupos, con el simple objetivo de dar, recibir y comprender.

Según Sueiro (2016), para que la comunicación tenga lugar, es necesario un propósito, expresado como un mensaje a transmitir. Este pasa a través de una fuente (emisor) y un receptor. A su vez, el mensaje es codificado y luego enviado, mediante algún medio al destinatario, quien debe interpretar dicha información. Atendiendo a lo antes expuesto, se debe acotar que la comunicación ocurre gracias a la relación existente, entre el emisor y receptor.

Por lo tanto, según Chiavenato (2010), cuando se trata de personas que desean o deben comunicar mensajes o señales, "el proceso de comunicación exige que la fuente píense y codifique sus ideas con palabras o símbolos que puedan transmitirse rumbo al canal, de donde lo recibe destinatario y decodifica las palabras o símbolos para entenderlos e interpretarlos como ideas o significados.

Por ello, la comunicación sólo es efectiva cuando el destinatario interpreta y comprende el mensaje, lo cual significa que la comunicación es un proceso de doble vía que implica retroalimentación. Sin embargo, cuando se trata de comunicación humana, el concepto se haya sujeto a ciertas complicaciones adicionales, pues cada persona tiene su propio sistema cognitivo, sus percepciones, sus valores personales y sus motivaciones, lo cual constituye un patrón individual de referencia que vuelve bastante personal y singular su interpretación de las cosas.

En este sentido, ese patrón individual actúa como filtro que acondiciona y acepta cualquier información o selecciona y rechaza toda aquella que no se adapte a este proceso o que lo amenace, existiendo una codificación perceptiva (percepción selectiva) que actúa como mecanismo de defensa para bloquear el mensaje juzgado 
como indeseable o no pertinente, pudiendo obrar sobre la recepción o el envío o peor aún, impedir la retroalimentación de la información. Esta aprehensión selectiva puede ser explicada a modo de metáfora como los lentes que utiliza el individuo para ver el mundo exterior e interpretarle a su manera.

Para finalizar, se acota los elementos de la comunicación son aquellos que van a permitir que el proceso se cumpla en su totalidad, donde el emisor, receptor y mensajes deben estar unificados o sincronizados para que el mismo se establezca de manera espontánea, facilitando el flujo de información en todas las direcciones.

\section{Emisor}

Para Gómez, Ruíz y Martí (2008), el emisor es el primer elemento del proceso de comunicación, el cual emite el mensaje al receptor, y en cualquier momento puede intercambiar los papeles transformándose en receptor y viceversa. En tal sentido, este se encarga de expresar las ideas que serán interpretadas por el receptor. En el mismo contexto, Saavedra y De la Cuesta (2010), afirman que el emisor es quien lanza el mensaje y puede ser una persona o un grupo de ellas. En las empresas todas las personas se comunican unas veces con otras de la propia organización, pero en ocasiones también suelen ser clientes u organismos oficiales. Al mismo tiempo, la institución también recibe mensajes de fuera.

Chiavenato (2010) acota que la fuente o emisor, en este caso es el sujeto que inicia el mensaje al codificar un pensamiento. Se han descrito cuatro condiciones que afectan la codificación del mensaje: la habilidad, la actitud, los conocimientos y el sistema sociocultural. El mensaje es el producto físico real de la fuente codificadora y puede ser lo que se habla, la escritura, la pintura y otros. Según Peñafiel y Serrano (2010), el emisor o codificador, es el punto (persona u organización) que elige y selecciona los signos adecuados para transmitir su mensaje. Es decir, los codifica para poder elevarlo de manera entendible al receptor. A su vez, expresan que el emisor son los participantes que crean y transmiten mensajes, utilizando señales verbales y no verbales. 
De lo expuesto anteriormente, para que las personas puedan entenderse necesitan manejar el mismo código que es el que va a permitir que ocurra la retroalimentación porque sin ella no fluiría el proceso. Todo ello conlleva a que los signos lingüísticos tienen que tener las mismas características, donde emisor y receptor cambian los papeles en un contexto dado.

Por su parte, Verdever, Sellnow y Verdever (2016), refiere que emisor es la persona que decide comunicar un mensaje, da forma a una serie de pensamientos o conceptos para que sean entendidos y asimilados por otra persona de la que se puede esperar una respuesta o no. En tal sentido, el emisor debe tener en cuenta una serie de aspectos antes de emitir su mensaje, por tanto, éste tiene que tomar en cuenta varios aspectos o decisiones sobre cómo será el mensaje en función de las características del receptor. Es decir, tiene que adecuar el mensaje al interlocutor.

Así todo emisor, debe estar consciente del mensaje que quiere expresar y que el mismo sea interpretado por el receptor correctamente para que ocurra eficazmente el proceso como tal, a su vez, los mensajes emitidos pueden ser interrumpidos, lo cual le dificulta a la fuente organizar la información, para lograr los objetivos propuestos. Finalmente, todo emisor debe utilizar un lenguaje adecuado, de acuerdo al contexto donde se realice el proceso comunicacional, para que el mismo emita los mensajes coherentemente y puedan llegar de manera rápida al receptor, es decir, él es la persona que emite el mensaje, que también es llamado fuente.

\section{Receptor}

En todo proceso comunicativo intervienen los receptores como aquel conjunto de individuos que reciben todas las informaciones o mensajes emitidos, donde los mismos deben ser entendidos o comprendidos, descifrando la idea para luego dar respuesta a todo lo que se ha expuesto con anterioridad, realizando el proceso de descodificación de los mismos. 
En criterio de Alcaraz y García (2010) definen receptor como el segundo elemento humano del proceso de comunicación que recibe la información dada por el emisor. Igualmente, Ocampo (2016), definen receptor o decodificador como la persona a la que se destina el mensaje. Además, realiza un proceso inverso al del emisor, ya que en él está el descifrar e interpretar lo que el emisor quiere dar a conocer. Asimismo, Verdever, Sellnow y Verdever (2016), afirman que los receptores son aquellas personas que procesan los mensajes y las conductas que le han sido transmitidas por los transistores.

De esto, el receptor es aquella persona que capta los mensajes que son dados por el emisor en un contexto diferente, donde los mensajes deben ser primeramente codificados y luego decodificados por este para observar si se da la retroalimentación, es decir, si se dio la comprensión del mensaje en su totalidad, lo cual evitaría los malos entendidos.

Al respecto, Chiavenato (2010), el receptor es el sujeto - objeto a quien se dirige el mensaje. Pero antes de que el mensaje pueda recibirse, sus símbolos deben traducirse a una forma que pueda entender el receptor. Por tal motivo, esto es la decodificación del mensaje. En el último eslabón en el proceso de comunicación es la retroalimentación donde se verifica si se tuvo éxito en la comunicación; en él se coloca el mensaje de regreso en el sistema y así evitar malos entendidos.

En tal sentido, Gómez, Ruíz y Martí (2008), refieren que el receptor da respuesta de la retroalimentación al emisor, es decir, hacerle comprender, no necesariamente por medio de palabras, que ha recibido el mensaje. Para el autor antes citado, el receptor es el encargado de descifrar información para luego interpretarla. Si el mismo da respuesta a los mensajes emitidos se logra la retroalimentación, ocurriendo de forma coherente y eficaz el proceso de comunicación entre ambos actores, permitiendo expresar criterios de una manera crítica y reflexiva.

En el mismo orden, se pude inferir que el receptor recibe todos los mensajes que son dados por el transmisor, donde las informaciones deben ser descifradas, estando enmarcadas en el mismo entorno, respetando las normas lingüísticas que se establecen 


\section{Marleivis Cujia}

Telos Vol. 21, No. 1 (2019). 192-220

en el acto comunicativo, donde se relaciona lo locutivo, ilocutivo y perlocutivo del lenguaje en cualquier proceso comunicacional.

\section{Mensaje}

Según Alcaraz y García (2010), el mensaje es el contenido a transmitir empapado de intencionalidad. Asimismo, Saavedra y De la Cuesta (2010) definen mensaje como lo que el comunicador quiere transmitir, aquello que debe recibir el receptor. De esto, se deduce que los mensajes pueden ser intencionados o no. En el primer caso, se comunica de forma expresiva para causar un efecto en quién lo recibe. En el segundo caso, es cuando los mensajes son inconscientes y en algunos de los casos no son decodificados por los receptores para que se dé claramente el proceso comunicacional en el entorno educativo.

A su vez, Verdever, Sellnow y Verdever (2016) mencionan que los mensajes son las emisiones verbales y las conductas no verbales que los transmisores utilizan para manifestar intenciones. Además, para comprender la manera en que son creados y recibidos. Para ello, se necesita entender su significado, símbolos, codificaciones y decodificaciones, así como también su forma u organización.

De acuerdo con lo expuesto, los mensajes son informaciones que se expresan verbalmente ya sea oral o escrita, que son transmitidos por los emisores y estos son los encargados que el mensaje llegue sin interrupciones al receptor, los mismos varían de acuerdo al contexto donde se establezca el acto comunicativo. En criterio de

Se infiere que los mensajes, ideas, situaciones que se quieran expresar, se debe hacer de manera sencilla, coherente, entre otros, y los mismos son las informaciones manejadas por el emisor, el cual tiene conocimiento del cómo, el por qué y para que la va enviar, y por supuesto, los receptores captan, almacenan e interpretan dichos mensajes. 


\section{Las Barreras Comunicacionales}

El proceso de comunicación está sujeto a una serie de condiciones que en algunos casos no favorecen la transmisión de información y el entendimiento que de ella se desprende. Asimismo, se entienden las barreras comunicacionales como el potencial de distorsión encontrado en el proceso de comunicación. Al respecto, Chiavenato (2010), el proceso de comunicación humana también está sujeto a lluvias y tempestades, pues existen barreras que sirven de obstáculos o resistencia a la comunicación entre las personas. Estas variables intervienen en el proceso de comunicación y lo afectan profundamente, de modo que el mensaje recibido es muy diferente del que fue enviado. Las barreras de comunicación pueden ser personales, físicas y semánticas.

Según criterio de Palomo (2017), el proceso de comunicación no es fácil y se pueden cometer errores en todas sus etapas. Cualquier ruido que bloquee el significado de lo que se está comunicando o que impida al receptor entenderlo, se considera una barrera de comunicación, por tal razón, hay que buscar soluciones alternativas para erradicarlas.

Por su parte, Hitt et al (2010), las barreras de comunicación son aquellas que rompen el acto comunicativo, ya sea por diferencias individuales entre los emisores y receptores, el código que se utiliza, las emociones, o los ruidos que son los principales factores físicos que interrumpen dicho proceso comunicacional, no permitiendo que se dé la retroalimentación

De esto, dichas barreras interfieren con la comunicación entre los individuos o grupos dentro de la misma institución. En este orden, la base de estas barreras está en la estructura jerárquica de la organización, empezando por los gerentes y finalizando por los obreros o en su defecto, cualquier persona que integre la comunidad escolar y que participe en los procesos académicos, administrativos que se realizan dentro de la organización. 


\section{Barreras Personales}

Las barreras personales son las interferencias derivadas de las limitaciones emociones y valores humanos del individuo y se relacionan con la conducta del emisor y el receptor, generan dificultades para lograr los objetivos de la comunicación. Esto influye directamente en la reacción al recibir el mensaje. Al respecto, González (2015), sostiene que las emociones actúan como filtro en casi toda la comunicación, transmitiendo nuevas interpretaciones de la realidad propiamente dicha. Estas barreras pueden ser la escucha deficiente, las emociones, las motivaciones y los sentimientos personales.

En este sentido, Bateman y Snell (2009), afirman que en conjunción las barreras psicológicas afectan los procesos perceptivos y de filtración de las personas dando lugar a malas interpretaciones. Los primeros por ser subjetivos en cuanto a motivos y actitudes de interés personal de la gente hacia el emisor y el mensaje, originan interpretaciones parciales.

En este sentido, Ocampo (2016), acota que las barreras personales pueden tener un origen fisiológico: si se ocasionan por malformaciones, disfunciones y otras limitantes funcionales de las personas que intervienen en el proceso. Las personas tienen percepciones diferentes y limitadas del mundo exterior de acuerdo con su personalidad. La producción de los símbolos que expresan el saje está sujeta a la capacidad del transmisor.

En relación a las barreras psicológicas, cabe mencionar que todos los hombres son distintos, tienen diferentes personalidades, por que nacen distintos temperamentos y en su vida tienen diferentes experiencias que conforman su carácter. Entre las principales barreras psicológicas pueden ser mencionadas: el agrado o desagrado, las tendencias a valorar, los valores emocionales y los prejuicios. 


\section{Barreras físicas}

En criterio de Chiavenato (2010), son Interferencias que se presentan en el ambiente donde ocurre la comunicación y se refieren a las interferencias que se presentan en el ambiente donde ocurre la comunicación; ejemplo de ello puede ser un ruido estático, entre otros, tales como: deficiencias en la selección inadecuada de la fuente de los medios utilizados para transportar el mensaje.

A su vez, la conceptualización de barreras físicas, según Palomo (2017) aborda las diferencias de los medios materiales empleados en la transmisión y recepción del mensaje, estas diferencias pueden ser de naturaleza puramente mecánica, eléctrica, magnéticas, acústicas, ópticas, entre otras, según el medio transmisor o receptor que se usa. Finalmente, la misma autora refiere que una conversación que pueda distraer, una puerta que se abre en el transcurso de la clase, un canal saturado, ruidos estáticos en la comunicación telefónica, entre estas barreras se encuentran interferencias, ruidos ambientales, distancia, a continuación, según el autor antes mencionado, se presentan cada una:

- Espacio fisco; las condiciones del espacio son determinantes para una buena comunicación encontrando problema de acústica que afectan la motivación y capacidad de codificación.

- Interferencia física; se entienden como la distorsión del sistema que establece contacto entre la fuente, el destino y el contenido del mensaje, es decir, se asocia con las debilidades del funcionamiento de algunos dispositivos del sistema de comunicación.

- Fallas mecánicas; se asocian con la aplicación de procedimientos y medios que forman parte del sistema de comunicación, sin embargo, cuando generan fallas técnicas se establecen espacios libres que cortan la transmisión del mensaje y de hecho el significado de este.

Ruidos ambientales; se entiende como una interferencia o líneas cruzadas que distorsionan la transmisión dinámica del mensaje, lo cual afecta el proceso y el significado del mensaje. 


\section{Marleivis Cujia}

Telos Vol. 21, No. 1 (2019). 192-220

- Distancia; es otra barrera física, la cual afecta la comunicación dependiendo de sistema conformado, de tal manera que la comunicación personal implica un acercamiento con fines de hacer llegar el mensaje y significado en las condiciones establecidas, sin embargo, cuando este sistema se ve influenciado por el uso de tecnología la distancia puede ser un factor que no modifica el significado y retroalimentación del mensaje.

- Sucesos locales; determinan una barrera en la medida que no puedan ser coordinados para garantizar un adecuado proceso de comunicación, lo cual deja claro que el suceso local determina en un nivel importante el contenido y la manera de difundirlo.

En algunos casos, las personas requieren privacidad para la ejecución de su trabajo; en otras, cuando se trata de atender a los empleados de la institución educativa o a la comunidad escolar, deberán estar ubicadas de manera que los docentes, gerentes y empleados administrativos puedan interactuar con los usuarios ofreciendo un servicio de manera abierta. De allí, que la barrera física más evidente en los procesos comunicacionales es el ruido que se genera en el entorno educativo, no permitiendo un entendimiento entre todos los miembros de estas porque los mensajes emitidos llegan distorsionados a todo el personal que se encuentran escuchando en ese momento.

Cabe resaltar que en las instituciones educativas deben cuidarse los espacios que van a conformar los ambientes de aprendizaje de los discentes, ya que esto repercute en el cumplimiento del proceso. En este sentido, el gerente y el docente deberán atender que tales escenarios educativos sean cónsonos con su área de desempeño, con la asignatura asignada, con la edad de los alumnos, favoreciendo espacios abiertos, claros, sencillos, sin retorno auditivo, que le permita la interactividad necesaria al logro de los propósitos educacionales. 


\section{Barreras Semánticas}

Las barreras semánticas se refieren a las limitaciones o distorsiones derivadas de los símbolos utilizados en la comunicación, Ejemplo: gestos, señales, símbolos, entre otros. El origen radica en problemas de sentido, significación, acepciones del lenguaje y en general de los símbolos que se utilizan y su decodificación, tomando en cuenta que las palabras presentan significados diferentes. Al respecto, Davis (2010) señala que las barreras semánticas se originan en las limitaciones de los símbolos a través de los cuales se comunica el sujeto, tanto en la comunicación verbal como no verbal. Las palabras imágenes y acciones tienen diferentes interpretaciones o significados según el individuo, en este caso las barreras semánticas se asocian con la interpretación de la palabra, traslación del lenguaje, entre otros.

Las barreras semánticas, se derivan del problema consistente en que los símbolos transmitidos transportan precisamente el significado deseado. La palabra, ya sea hablada o escrita es generalmente el símbolo usado en la comunicación administrativa, el hecho de que cada palabra tenga varias acepciones oficialmente reconocida y algunas otras sancionadas por el uso común, ya no es un obstáculo para lograr una comunicación efectiva.

En este orden, Muñoz y Valencia (2017), la comunicación puede ser recibida en forma bastante diferente de la que se ha intentado. Por ejemplo, la palabra utilidades puede representar para el ejecutivo una medida del éxito y un dividendo merecido por una compañera, mientras que para el empleado puede representar los fondos que debería haber recibido en forma de mayores salarios. La diferencia del significado en este caso está en las personas y no en las palabras.

Al respecto, Apolo et al., (2017), mencionan que dicha deformación se produce sobre todo por el proceso de especialización en las actividades que ocasiona, a su vez, una división semántica, vertical entre quienes piensan y quienes hacen, traducida en la comprensión diferencial de la operación que cada uno debe ejercer en función de la organización. 
Aunado a la idea anterior, Apolo et al (2017), acotan que estas barreras están relacionadas con los siguientes aspectos:

- Interpretación de las palabras; está determinada por la manera en que el mensaje experimenta alteraciones derivado de la interpretación de los símbolos utilizados en la comunicación. Traslación del lenguaje; la trasladación del lenguaje va a depender del canal sea escrito, verbal o gestual.

- Significado de las señales; las señales están determinadas por las formas de comunicación y pueden ser interpretadas de diferentes formas distorsionado el mensaje.

- Significado de símbolos; los símbolos están determinados por las formas de comunicación y pueden ser interpretadas de diferentes formas distorsionado el mensaje.

- Decodificación de gestos; está asociado con la manera como se hace comprensible el mensaje en el destinatario asociado directamente con los conocimientos, la percepción y la motivación instaurada.

- Sentido de recurso; este se asocia directamente con el contexto ambiental en el cual se proyecta el mensaje, con las posibilidades de retroalimentación como vía para centra la información.

Según González (2015), Las mismas palabras significan cosas diferentes para cosas distintas. Coincidentemente, Feijóo et al (2010), hacen referencia sobre la inhibición que las prácticas administrativas producen y su influencia en la correcta, clara, concisa y directa distribución de la información creando barreras de comunicación entre los diferentes niveles y entre los compañeros de departamentos de cada nivel.

Esto pudiere ser un estándar en comparación para evaluar el desempeño docente permitiendo una retroalimentación que influye en la calidad educativa, por lo tanto, requiere de un proceso de evaluación interna y externa. La primera se 
realiza centrada en sus funciones en la escuela y la segunda se vincula con su imagen y vinculado con la comunidad.

En igual sentido, refiere Ocampo (2016), que los obstáculos en la comunicación del gerente, igualmente, devienen de la cultura que tenga la persona, de tal manera que está conformada por el conjunto de creencias, hábitos, costumbres, valores, lo que permite dar significado a las cosas de manera distinta para cada sujeto interlocutor.

En este sentido, en el proceso comunicacional, en ocasiones el emisor envía un mensaje, que puede ser mal interpretado por el receptor, o lo envía de manera errónea con lo cual se percibe de manera distinta a la que había sido seleccionada. Esto impide, por supuesto, que la interacción se produzca de manera conveniente, lo que incluso puede afectar relaciones personales y, por ende, relaciones sociales y laborales.

De allí que se pueda inferir que, en el caso de las barreras semánticas de la comunicación, los gerentes y docentes objeto de estudio, al utilizar el lenguaje debe ser expresado con claridad entre todos los actores de las instituciones educativas investigadas, se deberá cuidar, además, el lenguaje corporal que acompañe al verbal, para evitar que esto pueda generar distorsiones de las informaciones dadas.

\section{Metodología}

Considerando todo lo expuesto con anterioridad, este artículo presentó un tipo de investigación descriptiva, el cual definido por Hernández, Fernández y Baptista (2010), es aquel que pretende responder a las interrogantes de la variable comunicación del gerente mostrando las características resaltantes. De lo anterior, resulta que el diseño fue no experimental transeccional, ya que el investigador observa los fenómenos tal y como ocurren naturalmente, sin intervenir en su desarrollo. Asimismo, el diseño fue transversal o transeccional, pues los criterios u opiniones de los grupos estudiados son tomados en un momento dado. (Hurtado, 2009). 


\section{Marleivis Cujia}

Telos Vol. 21, No. 1 (2019). 192-220

Con relación a la población tomada para analizar la comunicación del gerente, en primera instancia se seleccionaron tres instituciones educativas de básica secundaria, Institución Sagrada Familia, Institución el Carmelo, Institución Nuestra Señora de los Remedios quedando determinada por tres (3) directivos y (42) docentes para un total de 45 sujetos de las instituciones educativas públicas. Así, en lo que respecta a la muestra, tiene menos de 100.000 unidades, lo cual la hace finita.

El personal de estas instituciones mencionadas con anterioridad, cumple con algunas características básicas como estar activos, pertenecer al mismo nivel educativo, ser licenciados o licenciadas, estar colegiados, y por último, estar cursando estudio de cuarto nivel, considerando además, el distrito, cercanía, planificación y nivel de cada una de estas en Riohacha, Colombia. En este orden, se utilizó la observación por encuesta, mediante la elaboración de un cuestionario validado por siete (7) expertos especialistas en el área comunicacional con cinco alternativas de respuesta (Ver cuadro 1)

\section{Cuadro 1}

Distribución de la Población

\begin{tabular}{|l|l|l|}
\hline Instituciones de educación & Directores & Docentes \\
\hline Institución Sagrada Familia & 1 & 14 \\
\hline Institución el Carmelo & 1 & 14 \\
\hline Institución Nuestra Señora de los Remedios & 1 & 14 \\
\hline Total & 3 & 42 \\
\hline
\end{tabular}

Fuente: Elaboración propia

\section{Resultados}

Variable: Comunicación del gerente educativo 
Tabla 1. Elementos de la Comunicación

\begin{tabular}{|c|c|c|c|c|c|c|c|c|c|c|}
\hline \multirow[b]{2}{*}{ Alternativas } & \multicolumn{5}{|c|}{ Docentes } & \multicolumn{5}{|c|}{ Directores } \\
\hline & $\begin{array}{l}\overrightarrow{0} \\
.0 \\
\tilde{H}\end{array}$ & $\begin{array}{l}\tilde{0} \\
\stackrel{0}{0} \\
\stackrel{0}{0} \\
\simeq\end{array}$ & $\begin{array}{l}\frac{0}{\vec{J}} \\
\frac{0}{0} \\
\sum\end{array}$ & 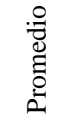 & $\%$ & 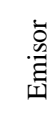 & $\begin{array}{l}\check{0} \\
\stackrel{0}{0} \\
\stackrel{0}{0}\end{array}$ & $\begin{array}{l}\cdot \frac{0}{\tilde{J}} \\
\tilde{0} \\
\sum_{\Sigma}^{0}\end{array}$ & 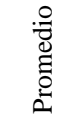 & $\%$ \\
\hline Siempre & 0,0 & 0,0 & 0,0 & 0,0 & 0,0 & 0.0 & 0.0 & 0.0 & 0,0 & 0.0 \\
\hline Casi siempre & 0,0 & 0,0 & 0,0 & 0,0 & 0,0 & 1,7 & 1 & 1,7 & 1,53 & 51 \\
\hline Algunas veces & 2,3 & 2,0 & 3,7 & 2,7 & 6,3 & 1,3 & 2 & 1,3 & 1,48 & 49 \\
\hline Casi nunca & 7,0 & 8,0 & 10,0 & 8,3 & 19,8 & 0.0 & 0.0 & 0.0 & 0,0 & 0.0 \\
\hline Nunca & 32,7 & 32,0 & 28,3 & 31 & 73,8 & 0.0 & 0.0 & 0.0 & 0,0 & 0.0 \\
\hline
\end{tabular}

Fuente: Elaboración propia

Muestra la Tabla 1, relativa a los elementos de la comunicación, que la mayoría de los docentes $(73,8)$ considera que nunca actúan como buenos emisores, ni receptores, así como tampoco construyen los mensajes con el cuidado necesario, además, el 19,8\% de los docentes opina que casi nunca se demuestra dichas cualidades en la institución, sólo el 6,3\% opina que algunas veces los docentes son buenos comunicadores.

Por otro lado, el $51 \%$ de los Directores encuestados consideran que casi siempre demuestran habilidades comunicativas. Pero, el $49 \%$ señala que sólo algunas veces.

Estos datos revelan una gran debilidad en cuanto a estos elementos, ya que se evidencian fallas en cada uno de los elementos, lo cual interrumpe el flujo comunicacional según explica Robbins (2009) para que la comunicación tenga lugar, es necesario un propósito, expresado como un mensaje a transmitir. Este pasa a través de una fuente (emisor) y un receptor. A su vez, el mensaje es codificado y luego enviado, mediante algún medio al destinatario, quien debe interpretar dicha información. Finalmente, los resultados son preocupantes, entendiendo la importancia de la comunicación y sus efectos en el entorno laboral y educativo. 
Tabla 2. Barreras de la Comunicación

\begin{tabular}{|c|c|c|c|c|c|c|c|c|c|c|}
\hline \multirow[b]{2}{*}{ Alternativas } & \multicolumn{5}{|c|}{ Docentes } & \multicolumn{5}{|c|}{ Directores } \\
\hline & 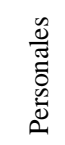 & 苞 & 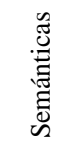 & 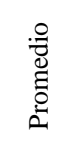 & $\%$ & 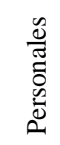 & 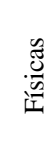 & 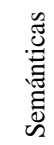 & 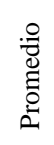 & $\%$ \\
\hline Siempre & 0,0 & 0,0 & 0,0 & 0,0 & 0,0 & 0.0 & 0.0 & 0.0 & 0,0 & 0.0 \\
\hline Casi siempre & 0,0 & 0,0 & 0,0 & 0,0 & 0,0 & 0,7 & 0,3 & 0,7 & 0,6 & 19 \\
\hline Algunas veces & 29,0 & 27,7 & 27,3 & 28,0 & 66,6 & 2,3 & 2,7 & 2,3 & 2,4 & 81 \\
\hline Casi nunca & 9,3 & 10,7 & 11,7 & 10,6 & 25,2 & 0.0 & 0.0 & 0.0 & 0,0 & 0.0 \\
\hline Nunca & 3,7 & 3,6 & 3,0 & 3,4 & 8,2 & 0.0 & 0.0 & 0.0 & 0,0 & 0.0 \\
\hline
\end{tabular}

Fuente: Elaboración propia

Con respecto a las barreras de la comunicación, en la tabla 2, el 66,6\% de los docentes asegura que algunas veces se atienden las mismas para evitar interferencias. Sin embargo, el $25,2 \%$ y el $8,2 \%$ señalaron que casi nunca y nunca se manejan estas barreras. Por su parte, el $81 \%$ de los Directores considera que algunas veces manejan las barreras de la comunicación, pero el 19\% casi siempre lo hace.

Se evidencia entonces que estos obstáculos están presentes ocasionalmente tanto en la comunicación de docentes como en directores, por lo que debe promoverse su manejo oportuno según plantea Palomo (2017), el proceso de comunicación no es fácil y se pueden cometer errores en todas sus etapas. Cualquier ruido que bloquee el significado de lo que se está comunicando o que impida al receptor entenderlo, se considera una barrera de comunicación, por tal razón, hay que buscar soluciones alternativas para erradicarlas.

Interpretando, existe una contradicción entre lo expresado por los docentes y por los rectores, en este orden, la comunicación del gerente en las instituciones seleccionadas posee muchas debilidades, mientras que los Directores consideran que si se establecen los elementos de la comunicación y se de una u otra forma se tratan de evitar las barreras de esta, los profesores se contraponen a esta idea, resultados similares a los reportados por Requeijo, (2010) quien determino que en las Instituciones educativas se necesita implementar un modelo de comunicación 
organizacional para elevar y mejorar la productividad del docente, donde se detectó la necesidad de participación y motivación en los docentes para lograr una acción eficiente y eficaz y así generar una educación con la calidad que se requiere para lograr los objetivos.

Lo cual exige un perfeccionamiento en el personal docente y directivo, a fin de contar con individuos capaces de construir comunicaciones efectivas, con características, valores y cualidades que le permitan obtener la retroalimentación necesaria para tomar decisiones acertadas que conduzcan el trabajo del plantel hacia una meta común, tal como lo refieren Koontz y Weihrich (2008).

Considerando la idea anterior, la capacitación docente se convierte en un pilar fundamental en las instituciones educativas de Riohacha, para un mejor desempeño del personal, mediante el uso de una comunicación efectiva que permita la interacción de todos los trabajadores en pro de lograr la calidad educativa desde la parte institucional como académica, fortaleciendo las relaciones interpersonales entre ellos para una participación continua en el desarrollo de todos los procesos y actividades que se planifiquen para el año escolar.

\section{Reflexiones Finales}

En continuidad con las ideas anteriores y en cuanto a analizar la comunicación del gerente en instituciones educativas de Riohacha en La Guajira, se puede acotar que los elementos de la comunicación son relevantes para que se dé el acto comunicativo en cualquier organización, además, se pudo constatar que, según los principales actores, esta presenta deficiencias al momento de efectuarse el acto comunicativo. Por otra parte, los gerentes educativos manifestaron que es aceptable el proceso comunicacional que se establece entre ellos y los docentes, observándose una divergencia en las respuestas emitidas; para los profesores existen muchas debilidades, mientras que para los directivos esta fluye porque se trata de evitar las barreras comunicacionales. 
Además, estas debilidades van a dificultar que las conversaciones se den de manera adecuada y que las informaciones sean comprendidas en su totalidad. En este orden, el acto comunicacional efectivo se presenta con dificultad. Por tal motivo, los mensajes deben ser claros y precisos, situación que no se presenta siempre en dichas instituciones.

Aunado a la idea anterior, se pudo evidenciar que existen debilidades tanto en el emisor como en el receptor y los mensajes emitidos, razón por la cual las informaciones establecidas no son codificadas y decodificadas en de manera adecuada. Por tal motivo, existe dificultad para comprender y poder emitir juicios asertivos, la falta de atención también se hace presente en los receptores, razón por la cual la idea expresada queda inconclusa.

Otro punto interesante, es que existe debilidad cuando establece conversaciones con sus trabajadores para la emisión de mensajes eficaces, desviando la atención de los procedimientos a seguir en el desarrollo de las actividades de la institución.

Por otra parte, en cuanto a las barreras presentes en el proceso de comunicación en algunos de los casos los docentes están atentos a las interferencias que pueden surgir al establecer el proceso de comunicación, a diferencia los directivos acotaron que ellos están atentos casi siempre. Observándose una disparidad entre las respuestas de los actores encuestados que intervienen en acto comunicativo.

Se tiene claro que en todas las instituciones educativas la comunicación es una herramienta necesaria para que se lleve a cabo las relaciones personales, el desarrollo de planes, programas o tareas en pro de mejorar la calidad de los procesos en el ámbito educacional. Desde allí, los directores como gerentes ejecutan acciones continuas como la evaluación, la supervisión, entre otras, interactuando constantemente con representantes, docentes, personal administrativo y obrero, que algunos de los casos tratan de mediar para solventar cualquier situación que se presente. 
Por tal motivo, las comunidades se guían por medio de las palabras, y su comprensión depende de la manera que estas llegan a los individuos. Cabe destacar que las relaciones que se establecen mediante esta, es muy relevante, porque permite un aprendizaje continuo.

Considerando lo anterior, hay diversos factores que intervienen y estos deberían ser tomados en cuenta a la hora de establecer la comunicación dentro de las instituciones educativas. Primeramente, recordar que los gerentes educativos son considerados un ente de comunicación efectiva, claro está esto ocurre mediante la implementación de la escucha activa, la empatía, el liderazgo transformacional, disminuyendo las barreras comunicacionales dentro del ámbito educacional, logrando una retroalimentación, haciendo uso efectivo de la información para el logro de los objetivos planificados a largo plazo.

Finalmente, todo el proceso comunicativo hay que establecerlo desde el respeto, la empatía, la tolerancia, aceptando las opiniones del otro como fortaleza institucional para la planificación de objetivos académicos, tratando de unificar los criterios en busca de soluciones pertinentes a cualquier problema mediante la toma de decisiones y una escucha activa efectiva, que conlleve al éxito organizacional.

\section{Referencias Bibliográficas}

Alcaraz, Antonio y García, María. (2010). Comunicación y TICS. Editorial Visión Libros. España

Apolo, Diego; Báez, Valerie; Pauker, Lizeth; Pasquel, Gabriela (2017) Gestión de Comunicación Corporativa: consideraciones para el abordaje de su estudio y práctica. Revista Latina de Comunicación Social, núm. 72. Universidad de La Laguna Canarias, España. (Pp. 521-539)

Bateman, Thomas y Snell, Scott. (2009). Administración. Liderazgo y colaboración en un mundo competitivo. McGraw Hill Interamericana. S.A. México.

Calderón, Carmen; Durán, Yimy; Meléndez Katheryn.; Rosero, Javier (2015). El papel de la Comunicación para el cambio social: empoderamiento y participación en contextos de violencia. Revista Encuentros, Universidad Autónoma del Caribe, Colombia, vol.13 (1), (Pp. 11-23). 
Chiavenato, Idalberto. (2010). Comportamiento organizacional. McGraw-Hill. Interamericana Editores, S.A. de C.V. México.

Davis, Flora (2010). La comunicación no verbal. FGS. España. Extraído de:

https://comunicacionenlaunsj.files.wordpress.com/2011/09/la-

comunicacic3b3n-no-verbal.pdf. Consulta: 02-09-2018

Davis, Keith y Newstron John (2003). Comportamiento humano en el trabajo. Mc Graw Hill. México.

Escudero, María. (2012). Comunicación y atención al cliente. Paraninfo. España. Feijóo, Claudio; Gómez, José; Martínez, Inmaculada (2010). Nuevas vías para la comunicación empresarial: publicidad en el móvil. Vol. 19, Núm. 2 ).

Extraído de:

https://recyt.fecyt.es/index.php/EPI/article/view/epi.2010.mar.04/21309Consu lta: 9-09-2018

Gómez, Josefa, Ruíz, Ana, Martí María, (2008). La Comunicación Oral. Arco/libros. España.

González, Sonia (2015). El ABC de la comunicación efectiva. Grupo Nelson.

Estados Unidos.

Hernández, Fernández y Baptista (2010. Metodología de la Investigación. McGraw Hill. México.

Hitt, Michael, Black Stewart y Porter Lyman (2010). Administración. Pearson Educación. México.

Hurtado, Jackeline. (2009). Metodología y Técnica de Investigación aplicada a la comunicación. Panapo. Venezuela.

Koontz, Harold y Weihrich, Heinz (2008). Administración una perspectiva global. McGraw Hill. México.

Méndez, Antonio (2009). Perspectiva sobre comunicación y sociedad. Artes Gráficas S.A. Universidad de Valencia. España.

Munch, Lourdes y García, José (2015). Fundamentos de administración. Tillas. México.

Muñoz, Doris. y Valencia, Juan (2017). Roles de la Comunicación organizacional en la Gestión del Conocimiento: oportunidades y desafíos a partir de experiencias de grandes empresas antioqueñas, Poliantea. Vol. 13. $\mathrm{N}^{\circ} 24$. Colombia. (Pp. 1- 25).

Ocampo, María (2016). Comunicación empresarial. Plan estratégico como herramienta gerencial $y$ nuevos retos del comunicador en las organizaciones. ECOE Ediciones. Colombia. 
Palomo, María. (2017). Liderazgo y motivación de los equipos de trabajo. Editorial ESIC. España.

Peñafiel Eva y Serrano, Cristina (2010). Habilidades sociales. Editex. España Requeijo, Paula. (2010), El estilo de comunicar de Barack Obama. CIC. Cuadernos de Información y Comunicación. Vol. 15, España. (Pp. 263-285).

Robbins, Stephen (2009). Administración. Pearson Educación. México

Robbins, Stephen, y Coulter, María. (2007). Administración. Prentice Hall. México.

Saavedra, Irene., y De La Cuesta, María. (2010). Introducción a la sostenibilidad y RSC. Editorial Netbiblio, S.L. España.

Sueiro, Enrique (2016). Saber Comunicar saber: Guía para practicar comunicación efectiva. ACCI. España.

Verdever, Kathlen, Sellnow Deanna y Verdever, Rudolph (2016). Comunicate. Cenage Learning. Fifteenth edition. USA. 